\title{
Trichoderma Asperellum as a Novel Source to Prepare Chitosan Oligosaccharides by Enzymatic Hydrolysis and Its Antimicrobial Activity
}

\section{Wang Siqiang}

Tianjin University of Science and Technology

Zhang Jinyu

Tianjin University of Science and Technology

Pan Lichao

Lanzhou University of Technology

Li Kun

Tianjin University of Science and Technology

\section{Wang Liuya}

Tianjin University of Science and Technology

zhenyuan zhu ( $\nabla$ zhyuanzhu@tust.edu.cn )

Tianjin University of Science and Technology https://orcid.org/0000-0001-8016-5240

\section{Research Article}

Keywords: Chitosan oligosaccharides, Trichoderma asperellum, Chitosan, Antimicrobial activity, Enzymatic hydrolysis

Posted Date: January 31st, 2022

DOI: https://doi.org/10.21203/rs.3.rs-1187303/v1

License: (1) (1) This work is licensed under a Creative Commons Attribution 4.0 International License. Read Full License 


\section{Abstract}

Chitosan oligosaccharides (COS), as an important biological functional component, are mainly produced from marine resources, while their source face great challenges, such as seasonal variation, discontinuity and demineralization. In this study, the chitosan was extracted by alkaline method from Trichoderma asperellum, and then it was degraded with enzymatic hydrolysis to obtain the COS. The physicochemical characterization of chitosan from Trichoderma asperellum was compared with commercial chitosan, including chitosan content, deacetylation degree, chemical group, and molecular weight. Then, the enzymatic hydrolysis rates of Trichoderma asperellum chitosan and commercial chitosan were similar, 89.37 and $91.56 \%$, respectively. Moreover, the composition of COS was tested by TLC, HPLC and MALDITOF, which results shown that Trichoderma asperellum COS was composed of chitotriose, chitopentaose and chitohexaose, and commercial COS was composed of chitotriose, chitotetraose, chitopentaose, chitohexaose and four acetylated chitohexaose. The antibacterial activity for Trichoderma asperellum COS was greatly stronger commercial COS. In conclusion, Trichoderma asperellum proved to be a novel potential source for COS production.

\section{Introduction}

COS are the degradation of chitosan composed of glucosamine linked by $\beta$ - $(1 \rightarrow 4)$-glycosidic bonds with lower than $20 \%$ degree of polymerization, and shorter chain lengths (Muanprasat et al., 2015), which possess a great potential in pharmacological and industrial applications (Benchamas et al., 2021; Yuan et al., 2019). Currently, the main commercial sources of chitosan are shrimp and crab shells (Oladzadabbasabadi et al., 2021; Sadiq et al., 2021). However, due to the discontinuity and seasonal variation of marine resources and the need for demineralization of seafood processing(Ghormade et al., 2017), finding a viable alternative raw material being one of the most interesting. The fungal cell wall is composed of a polysaccharide-based three-dimensional network, and contains mainly chitosan (Ban et al., 2018). Moreover, the fungi can be readily grown on cheap nutrients, and cell wall can be recovered by simple chemical procedures and constant quality and supply of the raw materials are possible (Pochanavanich et al., 2002). Therefore, fungi as a viable alternative material can be used to product chitosan and then degrade it to obtain COS.

Trichoderma species are recognized as biocontrol agents that control several plant diseases by producing secondary metabolites to inhibit the growth of pathogens, including bacterial(Nuankeaw et al., 2020). Some studies indicated that Trichoderma could produce some enzymes, such as $\beta$-1,3-glucanase, chitinase, peroxidase and polyphenol oxidase, which can be used for inhibiting the growth of bacterial in plants (Ishii et al., 2013; Vizcaino et al., 2005; Yue et al., 2021). As we all know, COS also have great potential in antibacterial activity (Yue et al., 2020). Huang et al. (2018) observed that chitosan oligosaccharides, isolated from shrimp shell waste, were more effective than chitosan in inhibiting growth of bacteria. Bi et al. (2021) also reported that a new geraniol conjugated chitosan oligosaccharide, which presented a significant inhibition effect on $E$. coli and $S$. aureus. However, antibacterial activity of COS produced from Trichoderma species is rarely reported. 
The preparation of COS from chitosan employs physical methods, chemical methods, and enzymatic methods (Benchamas et al., 2021). Physical methods, including microwave irradiation, ultraviolet irradiation and ultrasonic treatment (Liang et al., 2018), which are highly purified and simple in structure. But these methods gain the low yield of COS. Unlike physical methods, chemical methods produce COS in a high yield at a much lower cost. One of the most commonly used methods is acid hydrolysis, but this method may produce large amounts of toxic by-products that are harmful to the environment (Lodhi et al., 2014). Enzymatic hydrolysis has become an attractive and widely used method due to its high yield and high specificity. However, this method is still not feasible in mass production because of its high cost (Hoell et al., 2010). Hence, more researches focusing on the optimization of COS preparations via enzymatic hydrolysis are required.

The aim of this study was to product COS by enzymatic hydrolysis from Trichoderma asperellum, and proper enzymatic hydrolysis process was optimized via single factor experiments and orthogonal design. Furthermore, the composition and antimicrobial activity were studied and compared with commercial COS. This study would provide an investigation basis for the preparation of COS from fungus and as a potential antibacterial agent in the food field.

\section{Materials And Methods}

\section{Materials and reagents}

Trichoderma asperellum ZZY was isolated from contaminated soil and has been preserved in the China General Microbiological Culture Collection Center (CGMCC). The deposit number of ZZY is CGMCC No.12071. The commercial chitosan derived from shrimp shells were purchased from Sigma-Aldrich Co. (USA), which was named as Chitosan-2. The T-series dextran standards (T-10, 40, 70, 500, 2000) were purchased from Solarbio Co. (Beijing, China). All other chemicals used in this paper were of analytical grade. Escherichia coli (E. coli), Staphylococcus aureus (S. aureus), Bacillus subtilis (B. subtilis) and Salmonella bacilli (S. subtilis) were obtained from Tianjin University of Science and Technology.

\section{Culture conditions}

The strain was stored in $-4{ }^{\circ} \mathrm{C}$ and need to be activated for 3 generations on PDA solid medium. And inoculated in $100 \mathrm{~mL}$ of seed medium ( $2 \%$ glucose, $20 \%$ potato) and fermented with shaking $160 \mathrm{rpm}$ for 3 day at $25^{\circ} \mathrm{C}$. Then the seed medium was inoculated into $1000 \mathrm{~mL}$ of liquid-submerged fermentation medium and fermented for 7 days. After the mycelia under filtered and washed with distilled water were obtained, dried and grinded.

\section{Basic ingredient analysis of Trichoderma asperellum}

The total sugar content, protein content, fat content, cellulose content and ash content of Trichoderma asperellum were determined. Total sugar content was measured by the phenol-sulfuric acid colorimetric method (Dubois et al., 1956) using glucose as the standard. The protein content was determined by the 
Bradford method (Bradford, 1976) using bovineserum albumin as the standard. The fat content was determined by continuous Soxhlet extraction according to Kouřimská et al. (2021). The cellulose content was measured by anthrone- $\mathrm{H}_{2} \mathrm{SO}_{4}$ colorimetry according to Cheng et al. (2019). The ash content was measured according to the procedure of Oellig et al. (2020).

Extraction of chitosan from Trichoderma asperellum

Based on the references reported (Kaya et al., 2015; Santos-Moriano et al., 2018), the alkali method was used for the preparation of chitosan in this article. The Trichoderma asperellum powder was extracted with $\mathrm{NaOH}(6 \%, w / v)$ at $90^{\circ} \mathrm{C}$ for $2 \mathrm{~h}$. The insoluble parts, containing chitin, were filtered and washed to neutral for remove the protein and other small molecules. The deacetylation of chitin was reacted in $\mathrm{NaOH}(50 \%, w / v)$ at $110^{\circ} \mathrm{C}$ for $1 \mathrm{~h}$. Chitin will be turned to chitosan, included in the insoluble parts. After filtered and washed to neutral again, these parts would be extracted three times by acetic acid solution $(10 \%, \mathrm{w} / \mathrm{v})$ at $90^{\circ} \mathrm{C}$ for $2 \mathrm{~h}$ and solid-liquid ratio was 1:30. The extract solutions were collected together and were adjusted to $\mathrm{pH}=9$ with $\mathrm{NaOH}(1 \mathrm{~mol} / \mathrm{L})$ and set quietly for $6 \mathrm{~h}$ to precipitate chitosan. And the Trichoderma asperellum chitosan (Chitosan-1) was obtained after centrifugation, washed to neutral and dried.

\section{Physicochemical characterization of chitosan}

\section{FT-IR analysis}

The functional groups of Chitosan-1 and Chitosan-2 were measured with FT-IR. The sample of $1 \mathrm{mg}$ and dried $\mathrm{KBr}$ of $150 \mathrm{mg}$ were mixed and measured by FT-IR spectrometer (PerkinElmer Corp., USA) within the range of $4000-400 \mathrm{~cm}^{-1}$.

\section{Molecular weight distribution}

The chitosan samples were detected using HPLC (Agilent-1200, Agilent Technologies Co. Ltd., USA) with TSK-GEL G4000PWxI column (7.8 mm × 300 mm, Tokyo, Japan). Other related parameters: column temperature of $30^{\circ} \mathrm{C}$, volume of $20 \mathrm{uL}$, flow rate of $0.6 \mathrm{~mL} / \mathrm{min}$, mobile phase of distilled water. The glucans were used to make standard curve $\left(y=-0.35 x+8.9799, R^{2}=0.9835\right)$.

\section{Deacetylation degree and content of chitosan}

The degree of deacetylation was determined by the two-abrupt-potentiometric titration method (Y. Zhang et al., 2011). In brief, accurately disperse $0.2 \mathrm{~g}$ chitosan into $30 \mathrm{~mL} \mathrm{HCl}(0.1 \mathrm{~mol} / \mathrm{L})$ and added into $50 \mathrm{~mL}$ distilled water. Then it was titrated with $0.1 \mathrm{~mol} / \mathrm{L} \mathrm{NaOH}$ (alkaline titration), after the two abrupt $\mathrm{pH}$ changes, both the $\mathrm{pH}$ value and the consumption of $\mathrm{NaOH}$ (or $\mathrm{HCl}$ ) were recorded. The deacetylation degree was calculated using the volume curve of the acid-base titrant.

The content of the chitosan samples was measured with ninhydrin assay (Leane et al., 2004). Chitosan standard solution and $1 \%$ ninhydrin were mixed in sodium acetate buffer $(\mathrm{pH}=5.5)$, then was heated to 
boil and diluted with $60 \%$ ethanol. The curve was made according to the linear relationship between the concentration of chitosan standard and absorbance value at $570 \mathrm{~nm}\left(\mathrm{y}=7.264 \mathrm{x}-0.0097, \mathrm{R}^{2}=0.9981\right)$.

\section{Preparation of COS}

The COS were obtained by the enzymatic hydrolysis of chitosan. The chitosanase was added into different concentrations of chitosan solution at proper temperature to degrade the chitosan. After centrifugation at $4000 \mathrm{r} / \mathrm{min}$ for $10 \mathrm{~min}$, COS were obtained by drying the supernatant. The degradation products of Chitosan-1 and Chitosan-2 were named as COS-1 and COS-2, respectively. In addition, the precipitate were washed to $\mathrm{pH} 7$ and dried to calculate the rate of enzymatic hydrolysis. The effect of enzymatic temperature $\left(A, 30-50^{\circ} \mathrm{C}\right)$, enzymatic time $(B, 2-10 \mathrm{~h})$, enzymatic dosage $(C, 20-50 \mathrm{U} / \mathrm{g})$ and substrate concentration (D, $2-10 \%, w / v)$ on enzymatic hydrolysis rate was also investigated. Then based on the results of the single factor experiment, all factors were combined according to orthogonal experiments. The $L_{9}\left(3^{4}\right)$ orthogonal table was used for orthogonal design. The enzymatic hydrolysis rate was calculated using follow equation:

Enzymatic hydrolysis rate $(\%)=\frac{m_{1}-m_{2}}{m_{1}} \times 100$

Where $\mathrm{m}_{1}$ and $\mathrm{m}_{2}$ stand for the dry weight of chitosan sample, and residual weight of chitosan sample after enzymatic hydrolysis, respectively.

\section{Composition analysis}

\section{Thin layer chromatography (TLC) analysis}

COS samples $(2 \mathrm{mg})$ were added to $0.5 \mathrm{~mL}$ distilled water. The expansion agent was $\mathrm{n}$-butyl alcohol: water: acetic acid: ammonia $=10: 7: 7: 1(\mathrm{v}: \mathrm{v}: \mathrm{v}: \mathrm{v})$, and the colorants were $2.5 \mathrm{~g}$ diphenylamine, $5 \mathrm{~mL}$ phenylamin, $25 \mathrm{~mL}$ 85\% phosphoric acid, $1 \mathrm{~mL}$ drochloric acid and250 $\mathrm{mL}$ acetone (Zhu et al., 2012).

\section{HPLC analysis}

The COS-1 and COS-2 were dissolved with mobile phase (acetonitrile: water=3:1, v/v) to a concentration of $5 \mathrm{mg} / \mathrm{mL}$ and filtered. Chromatographic column: APS-2 HYPERSIL. And the remaining operations follow step 2.5.2.

\section{MALDI-TOF analysis of COS}

The COS-1 and COS-2 $(400 \mu \mathrm{g})$ were dissolved in $100 \mu \mathrm{L}$ methanol-water $(1: 1, \mathrm{v} / \mathrm{v})$ and mixed with 2, 5dihydroxy-benzoic acid (DHB) in equal proportions. Then the mixed solution was spotted on the sample target, natural dried and put into the BRUKER to access mass spectrometry data. The samples were detected with the detection mode of linear positive ions.

\section{Antibacterial activity}


The antimicrobial activity was measured using a disc diffusion test (L. Zhang et al., 2021). The E. coli, S. aureus, $B$. subtilis and $S$. subtilis were used to test the effect on the COS in inhibiting the growth of bacteria. COS-1 and COS-2 were dissolved with distilled water to different concentrations $(2,4,8,16$ and $32 \mathrm{mg} / \mathrm{mL}$ ) and filtrated. Then the nutrient agar was added into each plate and solidified. And $100 \mathrm{uL}$ bacterial suspension $\left(10^{7} \mathrm{cfu} / \mathrm{mL}\right.$ ) was spread on the surface of plates and a filter paper disk (diameter: 6 $\mathrm{mm}$, thickness: $1 \mathrm{~mm}$ ) containing COS-1 or COS-2 sample was placed in the plate. $2 \mathrm{mg} / \mathrm{mL}$ penicillin sodium was used as a positive control. Then these plates were incubated at $37^{\circ} \mathrm{C}$ for $24 \mathrm{~h}$. The antimicrobial activity of COS- 1 and COS- 2 was evaluated by determining the diameters of inhibitory zones with a vernier calipe. Determining the minimum inhibitory concentration (MIC) of COS were evaluated by double broth dilution method according to No et al. (2002) .

\section{Resuits And Discussion}

Main ingredient analysis of Trichoderma asperellum

The total sugar content, protein content, fat content, cellulose content and ash content of Trichoderma asperellum were determined, respectively. As shown in Table 1, the total sugar content of Trichoderma asperellum was very high, so it was suitable as a raw material for preparing COS. In addition, the Trichoderma asperellum contains a lot of cellulose and small account of protein, fat and ash.

Table 1

Basic composition of raw materials

\begin{tabular}{|llllll|}
\hline Basic ingredient content (\%) & Total sugar & Protein & Fat & cellulose & Ash \\
\hline Trichoderma asperellum & $25.30 \pm 1.27$ & $17.82 \pm 0.53$ & $12.44 \pm 0.76$ & $24.7 \pm 0.22$ & $12.35 \pm 0.42$ \\
\hline
\end{tabular}

\section{Physicochemical characterization of chitosan}

\section{Chitosan content, molecular weight and degree of deacetylation}

The extraction yield for Trichoderma asperellum chitosan was $9.53 \pm 0.02 \%$ and its chitosan content was $42.15 \pm 0.11 \%$. The molecular weight were shown in Fig. 1 (A), the main retention time of Chitosan- 1 was $13.796 \mathrm{~min}$ and the molecular weight distribution concentrated at $18 \mathrm{kDa}$, which calculated according to the retention times of standards. Affes et al. (2019) reported that the molecular weight from 142.19 to $1244.70 \mathrm{kDa}$ of chitosan in several shrimp shell materials was demonstrated. Generally, low molecular weight chitosan exhibits better solubility and has more prominent antibacterial, immuno-enhancing activity than and high molecular weight chitosan (X. Chen et al., 2017).

In addition, the chitosan of deacetylation extracted from Chitosan- $1(87.59 \pm 0.42 \%)$ was significantly higher than that of Chitosan-2 $(82.40 \pm 0.57 \%)$. It can be concluded that the Trichoderma asperellum is more easily in deacetylating chitin. Generally, chitosan with a higher degree of deacetylation would 
expose more active groups (Ma et al., 2022). Therefore, the chitosan in Trichoderma asperellum may have more potential in medicine than that in shrimp shells.

\section{FTIR spectrum analysis}

The date in Fig. 1 (B) presents the FT-IR spectrum of Chitosan-1 and Chitosan-2. FT-IR spectrum of Trichoderma asperellum chitosan was not different with commercial chitosan. Some prominent band $1661 \mathrm{~cm}^{-1} ه 1559 \mathrm{~cm}^{-1} \otimes 1315 \mathrm{~cm}^{-1}$ corresponded to the stretching vibration of $\mathrm{C}=\mathrm{O}$ (amide band I), $\mathrm{N}-\mathrm{H}$ (amide band II) and N-H (amide band II), and the signal near at $1118 \mathrm{~cm}^{-1}$ and $1072 \mathrm{~cm}^{-1}$ were due to CO-C and C-O stretching, which were characteristic band of chitosan (Khajavian et al., 2022). Besides the absorption peak at near $3356 \mathrm{~cm}^{-1}$ was attributed to the stretching vibration of $-\mathrm{OH}$. At the peaks around $2925 \mathrm{~cm}^{-1}$ assigned to $-\mathrm{CH}_{2}$, and the peak intensity of Chitosan-1 was higher than Chitosan-2.

\section{Preparation of COS by enzymatic hydrolysis \\ Single factor optimization results}

The effects of enzymatic temperature, enzymatic time, enzymatic dosage and substrate concentration on Chitosan-1 and Chitosan-2 enzymatic hydrolysis rate were determined using single factor experiments, and the results were presented in Fig. 2. As shown in Fig. 2(A), Chitosan-1 and Chitosan-2 enzymatic hydrolysis rate were remarkably increased with the temperature increased from 30 to $40{ }^{\circ} \mathrm{C}$, and reached to a maximum value of $86.34 \% \pm 0.86 \%$ and $88.92 \pm 1.34 \%$, respectively. Subsequently, the enzymatic hydrolysis rate was descended with extraction temperature of $50^{\circ} \mathrm{C}$, indicating that excessive temperature could degrade the chitoanase and leading to the hydrolysis rate reduction.

Figure 2(B) exhibited the effects of time on enzymatic hydrolysis rate with other conditions set to fixed values. Results showed that Chitosan- 1 and Chitosan-2 enzymatic hydrolysis rate were rapidly increased to $79.43 \pm 0.18 \%$ and $74.92 \pm 0.45 \%$ as the extraction time ascended to $6 \mathrm{~h}$, and then no significantly change. The hydrolysis rate has not changed due to the enzymatic hydrolysis reaction reached saturation.

Figure 2 (C) showed the effects of enzymatic dosage on enzymatic hydrolysis rate yields. As shown, there was a rapid rise of Chitosan-1 and Chitosan-2 enzymatic hydrolysis rate (maximum value of $87.78 \pm 0.29 \%$ and $88.97 \pm 1.02 \%$, respectively. ) with the enzyme dosage increased to $30 \mathrm{U} / \mathrm{g}$, then gradually decreased. These results indicated that appropriate enzyme dosage would promote the hydrolysis of chitosan, while the excessive enzyme dosage could cause damage of chitosan.

The effects of substrate concentration on enzymatic hydrolysis rate were presented in Fig. 2 (D). As shown, Chitosan-1 and Chitosan-2 enzymatic hydrolysis rate were firstly increased to peak value of 89.62 $\pm 0.29 \%$ and $90.04 \pm 0.48 \%$, respectively (substrate concentration of $8 \mathrm{~g} / \mathrm{mL}$ ), and then decreased with substrate concentration continuously raised to $10 \mathrm{~g} / \mathrm{mL}$. 
Therefore, enzymatic temperature of $50^{\circ} \mathrm{C}$, enzymatic time of $6 \mathrm{~h}$, enzymatic dosage of $30 \mathrm{U} / \mathrm{g}$ and substrate concentration of $8 \mathrm{~g} / \mathrm{mL}$ were selected as the intermediate values for further optimization in orthogonal design.

\section{Orthogonal design}

During the optimization experiments, 9 groups of experiments were carried out and the results of orthogonal design were shown in Table 2. The results showed that the enzymatic hydrolysis rate of chitosan- 1 was $80.13-89.37 \%$ by $L_{9}\left(3^{4}\right)$ orthogonal experiment design. Base on the maximum hydrolysis rate the optimum formulation was $A_{1} B_{2} C_{2} D_{2}$ (Run 2). And the optimal enzymatic hydrolysis conditions were enzymatic temperature of $37^{\circ} \mathrm{C}$, enzymatic time of $6 \mathrm{~h}$, enzymatic dosage of $30 \mathrm{U} / \mathrm{g}$, and substrate concentration of $8 \mathrm{~g} / \mathrm{L}$. Under this condition, the maximum hydrolysis rate was $89.37 \%$. The variance analysis were performed as shown in Table 3 , it indicated that the influence degree of the four factors on hydrolysis rate of Chitosan- 1 was $A>B>D>C$. In addition, the optimal resulted in a maximum Chitosan- 2 hydrolysis rate of $91.56 \%$, which formulation was $A_{3} B_{3} C_{2} D_{1}$ (Run 9). And the optimal enzymatic hydrolysis conditions were enzymatic temperature of $43^{\circ} \mathrm{C}$, enzymatic time of $7 \mathrm{~h}$, enzymatic dosage of $30 \mathrm{U} / \mathrm{g}$, and substrate concentration of $6 \mathrm{~g} / \mathrm{L}$. The influence degree of the four factors on hydrolysis rate of Chitosan-2 was $\mathrm{C}>\mathrm{A}>\mathrm{B}>\mathrm{D}$ (Table 3 ). 
Table 2

Orthogonal design and result analysis

\begin{tabular}{|c|c|c|c|c|c|c|}
\hline Run & $\mathrm{A}\left({ }^{\circ} \mathrm{C}\right)$ & B (h) & $\begin{array}{l}C \\
(U / g)\end{array}$ & $\begin{array}{l}\mathrm{D} \\
(\mathrm{g} / \mathrm{mL})\end{array}$ & $\begin{array}{l}\text { Enzymatic hydrolysis } \\
\text { rate of Chitosan-1 (\%) }\end{array}$ & $\begin{array}{l}\text { Enzymatic hydrolysis } \\
\text { rate of Chitosan-2 (\%) }\end{array}$ \\
\hline 1 & $1(37)$ & $1(5)$ & $1(28)$ & $1(6)$ & 80.13 & 70.18 \\
\hline 2 & 1 & $2(6)$ & $2(30)$ & $2(8)$ & 89.37 & 80.75 \\
\hline 3 & 1 & $3(7)$ & $3(32)$ & $3(10)$ & 87.41 & 78.24 \\
\hline 4 & $2(40)$ & 1 & 2 & 3 & 88.52 & 81.96 \\
\hline 5 & 2 & 2 & 3 & 1 & 89.17 & 87.02 \\
\hline 6 & 2 & 3 & 1 & 2 & 88.28 & 78.01 \\
\hline 7 & $3(43)$ & 1 & 3 & 2 & 88.54 & 82.58 \\
\hline 8 & 3 & 2 & 1 & 3 & 88.87 & 78.37 \\
\hline 9 & 3 & 3 & 2 & 1 & 88.34 & 91.56 \\
\hline \multirow{5}{*}{$\begin{array}{l}\text { Chitosan- } \\
1\end{array}$} & k1 & 83.57 & 84.78 & 84.87 & 85.18 & \\
\hline & k2 & 88.88 & 89.36 & 88.72 & 88.82 & \\
\hline & k3 & 88.51 & 86.82 & 87.37 & 86.96 & \\
\hline & Range & 5.31 & 4.58 & 3.85 & 3.64 & \\
\hline & Rank & \multicolumn{4}{|c|}{$A>B>D>C$} & \\
\hline \multirow{5}{*}{$\begin{array}{l}\text { Chitosan- } \\
2\end{array}$} & k1 & 76.49 & 77.60 & 76.31 & 82.19 & \\
\hline & k2 & 81.29 & 81.13 & 83.72 & 80.61 & \\
\hline & k3 & 83.31 & 82.36 & 81.06 & 78.29 & \\
\hline & Range & 6.82 & 4.76 & 7.41 & 3.9 & \\
\hline & Rank & \multicolumn{2}{|c|}{$C>A>B>D$} & & & \\
\hline
\end{tabular}


Table 3

Chitosan-1 and Chitosan-2 variance analysis of orthogonal experiment

\begin{tabular}{|c|c|c|c|c|c|c|}
\hline Samples & Source & $\begin{array}{l}\text { Sum of } \\
\text { squares }\end{array}$ & $\begin{array}{l}\text { degree of } \\
\text { freedom }\end{array}$ & $\begin{array}{l}\text { mean } \\
\text { square }\end{array}$ & $\begin{array}{l}\text { F- } \\
\text { value }\end{array}$ & significance \\
\hline \multirow{6}{*}{$\begin{array}{l}\text { Chitosan- } \\
1\end{array}$} & $A$ & 105.223 & 2 & 52.612 & 11.236 & $\star \star$ \\
\hline & B & 63.325 & 2 & 31.663 & 6.762 & * \\
\hline & C & 45.886 & 2 & 22.943 & 4.900 & * \\
\hline & D & 39.754 & 2 & 19.877 & 4.245 & \\
\hline & Error & 42.141 & 9 & 4.682 & & \\
\hline & Total & 296.330 & 17 & & & \\
\hline \multirow{6}{*}{$\begin{array}{l}\text { Chitosan- } \\
2\end{array}$} & A & 147.107 & 2 & 73.554 & 18.068 & $\star \star$ \\
\hline & B & 73.493 & 2 & 36.747 & 9.027 & $\star \star$ \\
\hline & C & 169.118 & 2 & 84.559 & 20.772 & ** \\
\hline & D & 46.246 & 2 & 23.123 & 5.680 & * \\
\hline & Error & 36.638 & 9 & 4.071 & & \\
\hline & Total & 472.603 & 17 & & & \\
\hline
\end{tabular}

In summary, under optimized conditions, the enzymatic hydrolysis rate of chitosan in Trichoderma asperellum was close to that in commercial products. Furthermore, the total sugar content of COS obtained after Trichoderma asperellum hydrolysis $(90.2 \pm 0.97 \%)$ was higher than that of commercial products $(88.5 \pm 1.14 \%)$. This indicated that Trichoderma asperellum can be used as a good source of raw materials for preparing COS.

\section{Composition analysis of COS-1 and COS-2}

\section{TLC analysis}

As shown in Fig. 3, the results showed that COS-1 and COS-2 contained a small amount of oligosaccharides. In addition, the oligosaccharides have a trailing effect, it could be inferred that COS-1 and COS-2 were mixture of oligosaccharides.

\section{HPLC analysis}

As shown in Fig. 4, the COS-1 was composed of three kinds of oligosaccharides that the retention time were $6.273,6.930$ and $11.466 \mathrm{~min}$. And COS-2 was composed of five kinds of oligosaccharides that the retention times were $5.794,6.821,8.571,10.245$ and $11.228 \mathrm{~min}$. These experimental results are consistent with the results in TLC analysis. 


\section{MALDI-TOF analysis}

Enzymatic hydrolysis products were analysis by MALDI-TOF to determine the components of chitosan oligosaccharides. As shown in Fig. 5 , the fragment ions ( $m / z 524.757,846.860$ and 1007.804$)$ of COS-1 were clearly monitored and assigned to the quasi-molecular ion peaks $[\mathrm{M}+\mathrm{Na}]^{+}$of chitotriose, chitopentaose, and chitohexaose (M. Chen et al., 2010). The molecular weight of glucosamine residue was $m / z 161$, which was also the relative molecular mass differences between main peaks $(m / z 524.721$, $685.799,846.880,1007.804)$. The COS-1 was constituted with three chitosan oligosaccharides, which was consistent with the analysis of HPLC and TLC about COS-1. Another the fragment ions $(\mathrm{m} / \mathrm{z} 524.721$, $685.799,846.880,1007.804,1175.516)$ of COS-2 were assigned to the quasi-molecular ion peaks $[\mathrm{M}+\mathrm{Na}]^{+}$of chitotriose, chitotetraose, chitopentaose, chitohexaose and four acetylated chitohexaose (Wang et al., 2012). The molecular weight of acetylized glucosamine residue was $m / z 167$, and this was the relative molecular mass differences between chitohexaose $(\mathrm{m} / \mathrm{z} 1007.804)$ and four acetylated chitohexaose ( $\mathrm{m} / \mathrm{z}$ 1175.516). The COS-2 was constituted with five chitosan oligosaccharides, which was consistent with the analysis of HPLC and TLC about COS-2.

\section{Antibacterial activity}

The disc diffusion test method was used to evaluate antibacterial activity of COS-1 and COS-2 against $E$. coli, S. aureus, B. subtilis and S. bacilli. As shown in Fig. 6, antibacterial activities of COS-1 and COS-2 presented a dose-dependent manner. Inhibitory zone diameter of COS-1 and COS-2 with different concentrations was presented in Table 4. When the chitosan oligosaccharides concentration was 8 $\mathrm{mg} / \mathrm{mL}$, only inhibitory zones of COS-1 against $S$. bacilli was $10.45 \mathrm{~mm}$. Then as the concentration of chitosan oligosaccharides increased, inhibitory zones of COS-1 and COS-2 against these four bacteria was increased. When the concentration increased to $32 \mathrm{mg} / \mathrm{mL}$, inhibitory zones of COS-1 against $E$. coli, S. aureus, $B$. subtilis and $S$. bacilli were $10.48,11.12,8.46,11.45 \mathrm{~mm}$, and the corresponding inhibitory zones of COS-2 were 7.75, 8.52, 8.05 and $8.88 \mathrm{~mm}$, respectively. These results indicated that COS-1 and COS-2 inhibited the growth of four bacteria in this study, inhibitory effects of COS-1 was higher than COS2 at the same concentration, especially $S$. bacilli. 
Table 4

Inhibitory zone diameter of COS-1 and COS-2 with different concentrations (mm)

\begin{tabular}{|c|c|c|c|c|c|c|c|c|}
\hline \multirow{2}{*}{$\begin{array}{l}\text { Concentration of cOS } \\
(\mathrm{mg} / \mathrm{mL})\end{array}$} & \multicolumn{2}{|l|}{ E. coli } & \multicolumn{2}{|c|}{ S. aureus } & \multicolumn{2}{|c|}{ B. subtilis } & \multicolumn{2}{|c|}{ S. bacilli } \\
\hline & $\begin{array}{l}\text { cos- } \\
1\end{array}$ & $\begin{array}{l}\text { COS- } \\
2\end{array}$ & $\begin{array}{l}\text { COS- } \\
1\end{array}$ & $\begin{array}{l}\text { COS- } \\
2\end{array}$ & $\begin{array}{l}\text { cos- } \\
1\end{array}$ & $\begin{array}{l}\text { cos- } \\
2\end{array}$ & $\begin{array}{l}\text { cos- } \\
1\end{array}$ & $\begin{array}{l}\text { cos- } \\
2\end{array}$ \\
\hline 2 & 0.00 & 0.00 & 0.00 & 0.00 & 0.00 & 0.00 & 0.00 & 0.00 \\
\hline 4 & 0.00 & 0.00 & 0.00 & 0.00 & 0.00 & 0.00 & 0.00 & 0.00 \\
\hline 8 & 0.00 & 0.00 & 0.00 & 0.00 & 0.00 & 0.00 & 10.54 & 0.00 \\
\hline 16 & 7.65 & 6.54 & 9.43 & 6.58 & 8.24 & 7.54 & 10.62 & 6.52 \\
\hline 32 & 10.48 & 7.75 & 11.12 & 8.52 & 8.46 & 8.05 & 11.45 & 8.88 \\
\hline $\begin{array}{l}\text { Penicillin sodium } \\
(2 \mathrm{mg} / \mathrm{mL})\end{array}$ & 11.23 & 10.75 & 11.55 & 11.5 & 12.00 & 10.75 & 10.25 & 14.88 \\
\hline
\end{tabular}

Furthermore, the lowest concentrations of COS-1 and COS-2 prevented bacteria growth were also investigated (Table 5). MICs of COS-1 against E. coli, S. aureus, B. subtilis and S. bacilli were 15.80, 15.57, 15.72 and $6.87 \mathrm{mg} / \mathrm{mL}$, respectively. And the corresponding MICs of COS-2 were 15.93, 15.93, 15.80 and $15.90 \mathrm{mg} / \mathrm{mL}$, respectively. In a word, Trichoderma asperellum COS showed stronger antibacterial activity than commercial COS.

Table 5

Minimal inhibitory concentration (MIC) of COS-1 and COS-2 $(\mathrm{mg} / \mathrm{mL})$

\begin{tabular}{|lllll|}
\hline Samples & E. coli & S. aureus & B. subtilis & S. bacilli \\
\hline COS-1 & 15.80 & 15.57 & 15.72 & 6.87 \\
COS-2 & 15.93 & 15.93 & 15.80 & 15.90 \\
\hline
\end{tabular}

The antibacterial activity of chitosan oligosaccharides is greatly dependent on its physicochemical properties, especially degree of deacetylation and molecular weight (Benchamas et al., 2021). The molecular weight reduction and higher degree of deacetylation of chitosan or chitosan oligosaccharides would expose more active groups, and making which had better bioactivities (Meng et al., 2012). This might explain stronger antibacterial activity of COS-1 than COS-2. Moon et al. (2007) have reported that chitosan oligosaccharides with a higher degree of deacetylation tended to have a higher bactericidal action against Staphylococcus aureus. Huang et al. (2018) have reported that an increase in molecular weight leaded to decrease in the antibacterial activity of chitosan from squid (IIlex argentinus).

\section{Conclusions}


A new COS was prepared by enzymatic hydrolysis from Trichoderma asperellum. The optimal enzymatic hydrolysis conditions for Trichoderma asperellum chitosan were enzymatic temperature of $37^{\circ} \mathrm{C}$, enzymatic time of $6 \mathrm{~h}$, enzymatic dosage of $30 \mathrm{U} / \mathrm{g}$, and substrate concentration of $8 \mathrm{~g} / \mathrm{L}$. Under this condition, the maximum hydrolysis rate was $89.37 \%$. The composition of Trichoderma trichoderma COS was determined by MALDI-TOF, including chitotriose, chitotetraose, chitopentaose, chitohexaose and four acetylated chitohexaose. Besides, the antibacterial activity for Trichoderma asperellum COS against $E$. coli, S. aureus, B. subtilis and S. subtilis were greatly stronger compared to commercial COS. In conclusion, Trichoderma asperellum can be used as a good raw material for the preparation of COS and applied as a potential antibacterial agent in the food field.

\section{Declarations}

\section{Author Contribution Statement}

ZZY conceived and designed research. ZJY conducted experiments. LK and WLY contributed new reagents or analytical tools. PLC and WSQ analyzed data. WSQ wrote the manuscript. All authors read and approved the manuscript.

\section{Acknowledgments}

This work was financially supported by the Technology Program of Tianjin, China (20YFZCSN00210).

\section{Conflict of interest}

We declare that we have no financial and personal relationships with other people or organizations.

\section{Ethical approval}

This article does not contain any studies with human participants or animals performed by any of the authors.

\section{References}

1. Affes S, Aranaz I, Hamdi M, Acosta N, Ghorbel-Bellaaj O, Heras Á, Maalej H (2019) Preparation of a crude chitosanase from blue crab viscera as well as its application in the production of biologically active chito-oligosaccharides from shrimp shells chitosan. Int J Biol Macromol 139:558-569. doi:https://doi.org/10.1016/j.ijbiomac.2019.07.116

2. Ban Z, Horev B, Rutenberg R, Danay O, Bilbao C, McHugh T, Poverenov E (2018) Efficient production of fungal chitosan utilizing an advanced freeze-thawing method; quality and activity studies. Food Hydrocolloids 81:380-388. doi:https://doi.org/10.1016/j.foodhyd.2018.03.010

3. Benchamas G, Huang G, Huang S, Huang H (2021) Preparation and biological activities of chitosan oligosaccharides. Trends Food Sci Technol 107:38-44. 
doi:https://doi.org/10.1016/j.tifs.2020.11.027

4. Bi R, Yue L, Niazi S, Khan IM, Sun D, Wang B, Xia W (2021) Facile synthesis and antibacterial activity of geraniol conjugated chitosan oligosaccharide derivatives. Carbohydr Polym 251:117099. doi:https://doi.org/10.1016/j.carbpol.2020.117099

5. Bradford MM (1976) A rapid and sensitive method for the quantitation of microgram quantities of protein utilizing the principle of protein-dye binding. Anal Biochem 72(1-2):248-254. doi:https://doi.org/10.1016/0003-2697(76)90527-3

6. Chen M, Zhu X, Li Z, Guo X, Ling P (2010) Application of matrix-assisted laser desorption/ionization time-of-flight mass spectrometry (MALDI-TOF-MS) in preparation of chitosan oligosaccharides (COS) with degree of polymerization (DP) 5-12 containing well-distributed acetyl groups. Int J Mass spectrom 290(2):94-99. doi:https://doi.org/10.1016/j.ijms.2009.12.008

7. Chen X, Yang H, Zhong Z, Yan N (2017) Base-catalysed, one-step mechanochemical conversion of chitin and shrimp shells into low molecular weight chitosan. Green Chem 19(12):2783-2792. doi:https://doi.org/10.1039/C7GC00089H

8. Cheng J, Wen S, Bie Z (2019) Overexpression of hexose transporter CsHT3 increases cellulose content in cucumber fruit peduncle. Plant Physiol Biochem 145:107-113.

doi:https://doi.org/10.1016/j.plaphy.2019.10.034

9. Dubois M, Gilles KA, Hamilton JK, Rebers Pt, Smith F (1956) Colorimetric method for determination of sugars and related substances. Anal Chem 28(3):350-356

10. Ghormade V, Pathan E, Deshpande M (2017) Can fungi compete with marine sources for chitosan production? Int J Biol Macromol 104:1415-1421

11. Hoell IA, Vaaje-Kolstad G, Eijsink VG (2010) Structure and function of enzymes acting on chitin and chitosan. Biotechnol Genet Eng Rev 27(1):331-366.

doi:https://doi.org/10.1080/02648725.2010.10648156

12. Huang C-Y, Kuo C-H, Wu C-H, Ku M-W, Chen P-W (2018) Extraction of crude chitosans from squid (Illex argentinus) pen by a compressional puffing-pretreatment process and evaluation of their antibacterial activity. Food Chem 254:217-223. doi:https://doi.org/10.1016/j.foodchem.2018.02.018

13. Ishii T, Nonaka K, Suga T, Masuma R, Ōmura S, Shiomi K (2013) Cytosporone S with antimicrobial activity, isolated from the fungus Trichoderma sp. FKI-6626. Bioorg. Med Chem Lett 23(3):679-681. doi:https://doi.org/10.1016/j.bmcl.2012.11.113

14. Kaya M, Baublys V, Šatkauskienè I, Akyuz B, Bulut E, Tubelytė V (2015) First chitin extraction from Plumatella repens (Bryozoa) with comparison to chitins of insect and fungal origin. Int J Biol Macromol 79:126-132. doi:https://doi.org/10.1016/j.ijbiomac.2015.04.066

15. Khajavian M, Vatanpour V, Castro-Muñoz R, Boczkaj G (2022) Chitin and derivative chitosan-based structures - Preparation strategies aided by deep eutectic solvents: A review. Carbohydr Polym 275:118702. doi:https://doi.org/10.1016/j.carbpol.2021.118702

16. Kouřimská L, Pokhrel K, Božik M, Tilami SK, Horčička P (2021) Fat content and fatty acid profiles of recently registered varieties of naked and hulled oats with and without husks. J Cereal Sci 
99:103216. doi:https://doi.org/10.1016/j.jcs.2021.103216

17. Leane M, Nankervis R, Smith A, Illum L (2004) Use of the ninhydrin assay to measure the release of chitosan from oral solid dosage forms. Int J Pharm 271(1-2):241-249.

doi:https://doi.org/10.1016/j.ijpharm.2003.11.023

18. Liang S, Sun Y, Dai X (2018) A review of the preparation, analysis and biological functions of chitooligosaccharide. Int J Mol Sci 19(8):2197. doi:https://doi.org/10.3390/ijms19082197

19. Lodhi G, Kim Y-S, Hwang J-W, Kim S-K, Jeon Y-J, Je J-Y, Park P-J (2014) Chitooligosaccharide and its derivatives: preparation and biological applications. BioMed research international, 2014, 654913 doi:https://doi.org/10.1155/2014/654913

20. Ma J, Faqir Y, Tan C, Khaliq G (2022) Terrestrial insects as a promising source of chitosan and recent developments in its application for various industries. Food Chem 373:131407.

doi:https://doi.org/10.1016/j.foodchem.2021.131407

21. Meng X, Xing R, Liu S, Yu H, Li K, Qin Y, Li P (2012) Molecular weight and pH effects of aminoethyl modified chitosan on antibacterial activity in vitro. Int J Biol Macromol 50(4):918-924. doi:https://doi.org/10.1016/j.ijbiomac.2012.01.018

22. Moon J-S, Kim H-K, Koo HC, Joo Y-S, Nam H-m, Park YH, Kang M-I (2007) The antibacterial and immunostimulative effect of chitosan-oligosaccharides against infection by Staphylococcus aureus isolated from bovine mastitis. Appl Microbiol Biotechnol 75(5):989-998. doi: https://doi.org/10.1002/jsfa.3432

23. Muanprasat C, Wongkrasant P, Satitsri S, Moonwiriyakit A, Pongkorpsakol P, Mattaveewong T, Chatsudthipong V (2015) Activation of AMPK by chitosan oligosaccharide in intestinal epithelial cells: Mechanism of action and potential applications in intestinal disorders. Biochem Pharmacol 96(3):225-236. doi:https://doi.org/10.1016/j.bcp.2015.05.016

24. No HK, Park NY, Lee SH, Meyers SP (2002) Antibacterial activity of chitosans and chitosan oligomers with different molecular weights. Int J Food Microbiol 74(1-2):65-72. doi:https://doi.org/10.1016/S0168-1605(01)00717-6

25. Nuankeaw K, Chaiyosang B, Suebrasri T, Kanokmedhakul S, Lumyong S, Boonlue S (2020) First report of secondary metabolites, Violaceol I and Violaceol II produced by endophytic fungus, Trichoderma polyalthiae and their antimicrobial activity. Mycoscience 61(1):16-21. doi:https://doi.org/10.1016/j.myc.2019.10.001

26. Oellig C, Link K, Schwack W (2020) Characterization of E 472 food emulsifiers-Determination of bound and free fruit acids, free glycerol and ash content. J Chromatogr A 1619:460946. doi:https://doi.org/10.1016/j.chroma.2020.460946

27. Oladzadabbasabadi N, Nafchi AM, Ariffın F, Wijekoon MJO, Al-Hassan A, Dheyab MA, Ghasemlou M (2021) Recent advances in extraction, modification, and application of chitosan in packaging industry. Carbohydr Polym 118876. doi:https://doi.org/10.1016/j.carbpol.2021.118876

28. Pochanavanich $P$, Suntornsuk W (2002) Fungal chitosan production and its characterization. Lett Appl Microbiol 35(1):17-21. doi:https://doi.org/10.1046/j.1472-765X.2002.01118.x 
29. Sadiq AC, Olasupo A, Ngah WSW, Rahim NY, Suah FBM (2021) A decade development in the application of chitosan-based materials for dye adsorption: A short review. Int J Biol Macromol 191(30):1151-1163. doi:https://doi.org/10.1016/j.ijbiomac.2021.09.179

30. Santos-Moriano P, Kidibule PE, Alleyne E, Ballesteros AO, Heras A, Fernandez-Lobato M, Plou FJ (2018) Efficient conversion of chitosan into chitooligosaccharides by a chitosanolytic activity from Bacillus thuringiensis. Process Biochem 73:102-108. doi:https://doi.org/10.1016/j.procbio.2018.07.017

31. Vizcaino JA, Sanz L, Basilio A, Vicente F, Gutierrez S, Hermosa MR, Monte E (2005) Screening of antimicrobial activities in Trichoderma isolates representing three Trichoderma sections. Mycol Res 109(12):1397-1406. doi:https://doi.org/10.1017/S0953756205003898

32. Wang S-L, Liu C-P, Liang T-W (2012) Fermented and enzymatic production of chitin/chitosan oligosaccharides by extracellular chitinases from Bacillus cereus TKU027. Carbohydr Polym 90(3):1305-1313. doi:https://doi.org/10.1016/j.carbpol.2012.06.077

33. Yuan X, Zheng J, Jiao S, Cheng G, Feng C, Du Y, Liu H (2019) A review on the preparation of chitosan oligosaccharides and application to human health, animal husbandry and agricultural production. Carbohydr Polym 220:60-70. doi:https://doi.org/10.1016/j.carbpol.2019.05.050

34. Yue L, Sun D, Mahmood Khan I, Liu X, Jiang Q, Xia W (2020) Cinnamyl alcohol modified chitosan oligosaccharide for enhancing antimicrobial activity. Food Chem 309:125513. doi:https://doi.org/10.1016/j.foodchem.2019.125513

35. Yue L, Wang M, Khan IM, Niazi S, Wang B, Ma X, Xia W (2021) Preparation and characterization of chitosan oligosaccharide derivatives containing cinnamyl moieties with enhanced antibacterial activities. LWT 147:111663. doi:https://doi.org/10.1016/j.Iwt.2021.111663

36. Zhang L, Ma L, Pan Y, Zheng X, Sun Q, Wang Z, Qiao H (2021) Effect of molecular weight on the antibacterial activity of polysaccharides produced by Chaetomium globosum CGMCC 6882. Int J Biol Macromol 188:863-869. doi:https://doi.org/10.1016/j.ijbiomac.2021.08.059

37. Zhang Y, Zhang X, Ding R, Zhang J, Liu J (2011) Determination of the degree of deacetylation of chitosan by potentiometric titration preceded by enzymatic pretreatment. Carbohydr Polym 83(2):813-817. doi:https://doi.org/10.1016/j.carbpol.2010.08.058

38. Zhu Z-Y, Lian H-Y, Si C-L, Liu Y, Liu N, Chen J, Zhang Y (2012) The chromatographic analysis of oligosaccharides and preparation of 1-kestose and nystose in yacon. Int J Food Sci Nutr 63(3):338342. doi:https://doi.org/10.3109/09637486.2011.627847

\section{Figures}



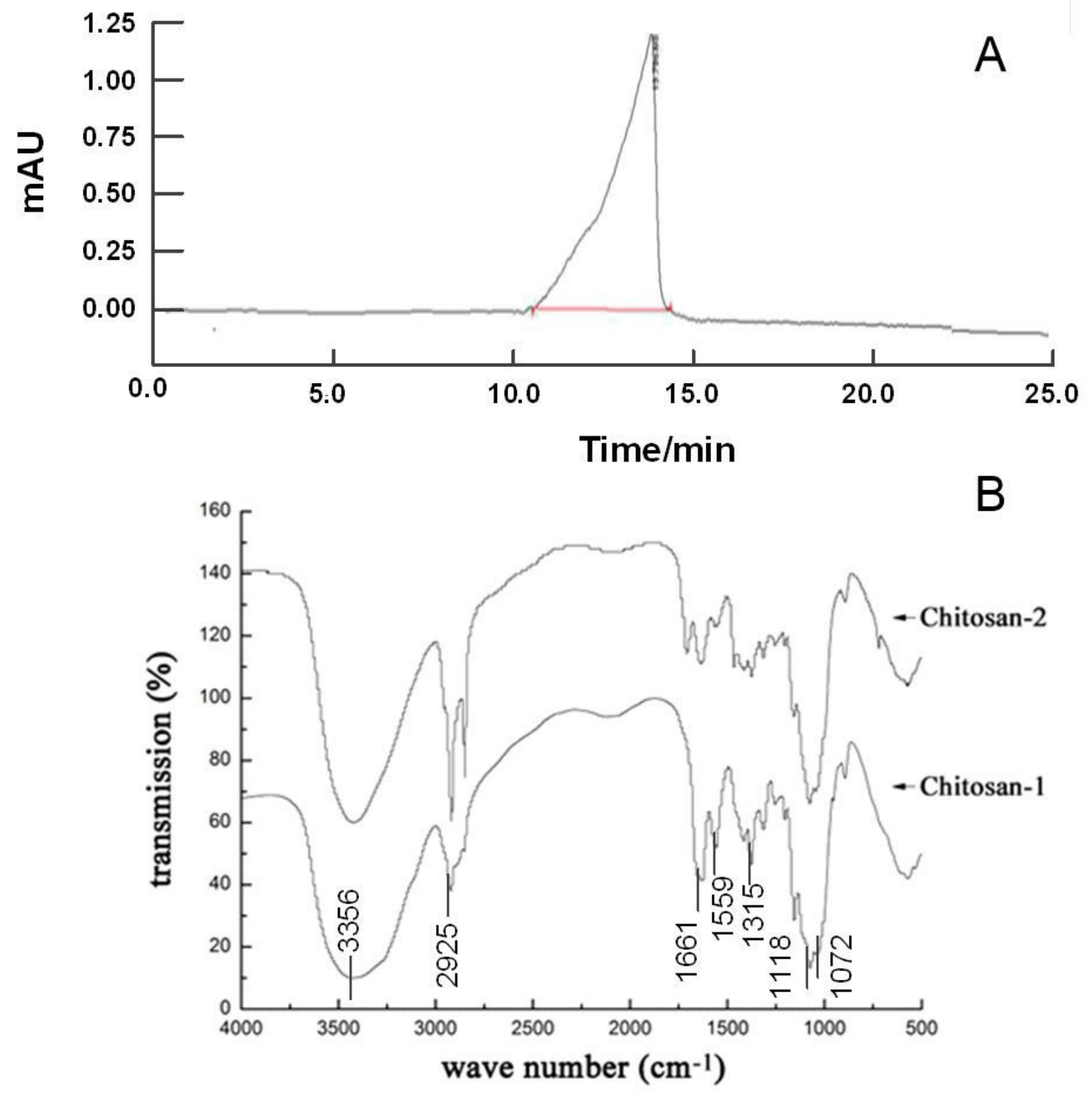

Figure 1

(A) The HPLC of Trichoderma asperellum chitosan. (B) The FT-IR spectra of Chitosan-1 and Chitosan-2. 

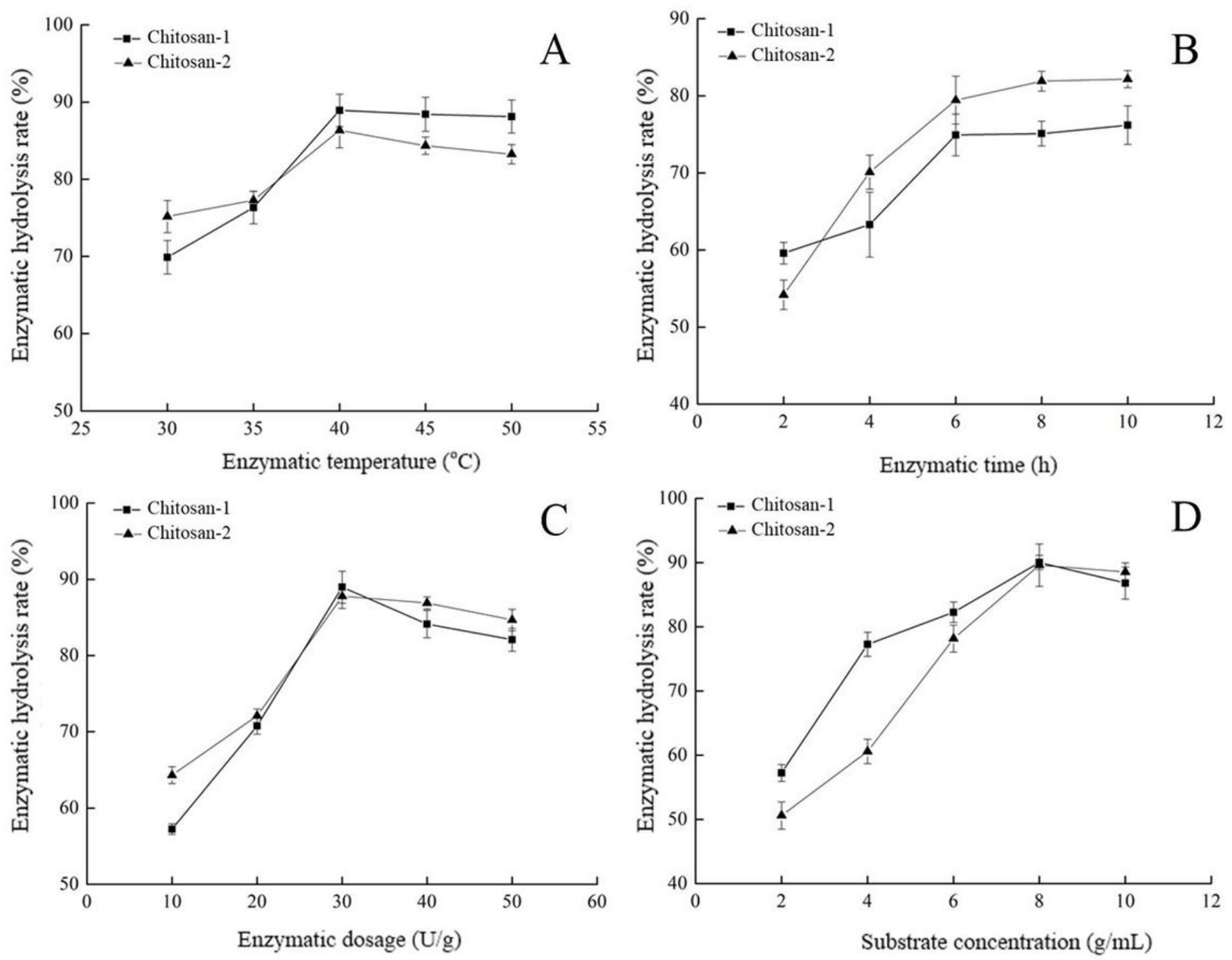

Figure 2

Effects of enzymatic temperature (A), enzymatic time (B), enzymatic dosage (C) and substrate concentration (D) on Chitosan-1 and Chitosan-2 enzymatic hydrolysis rate. 


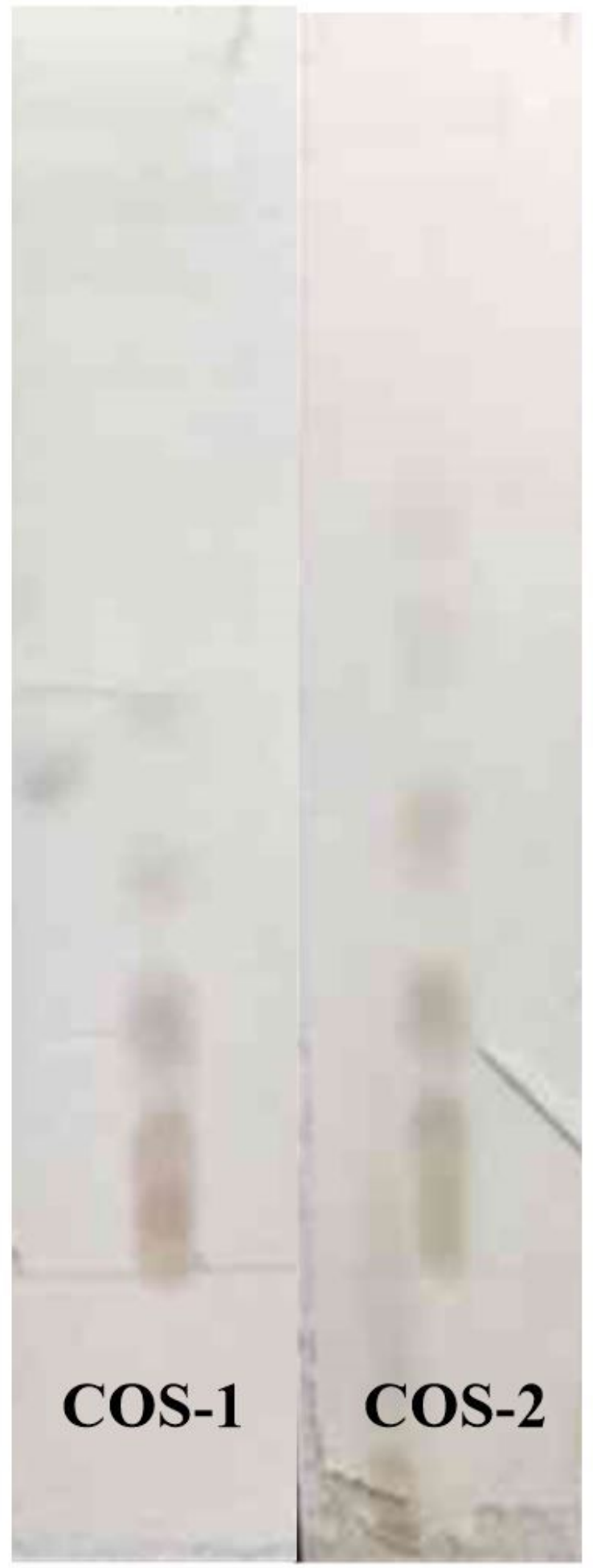

Figure 3

Thin layer chromatograms of COS-1 and COS- 2 . 

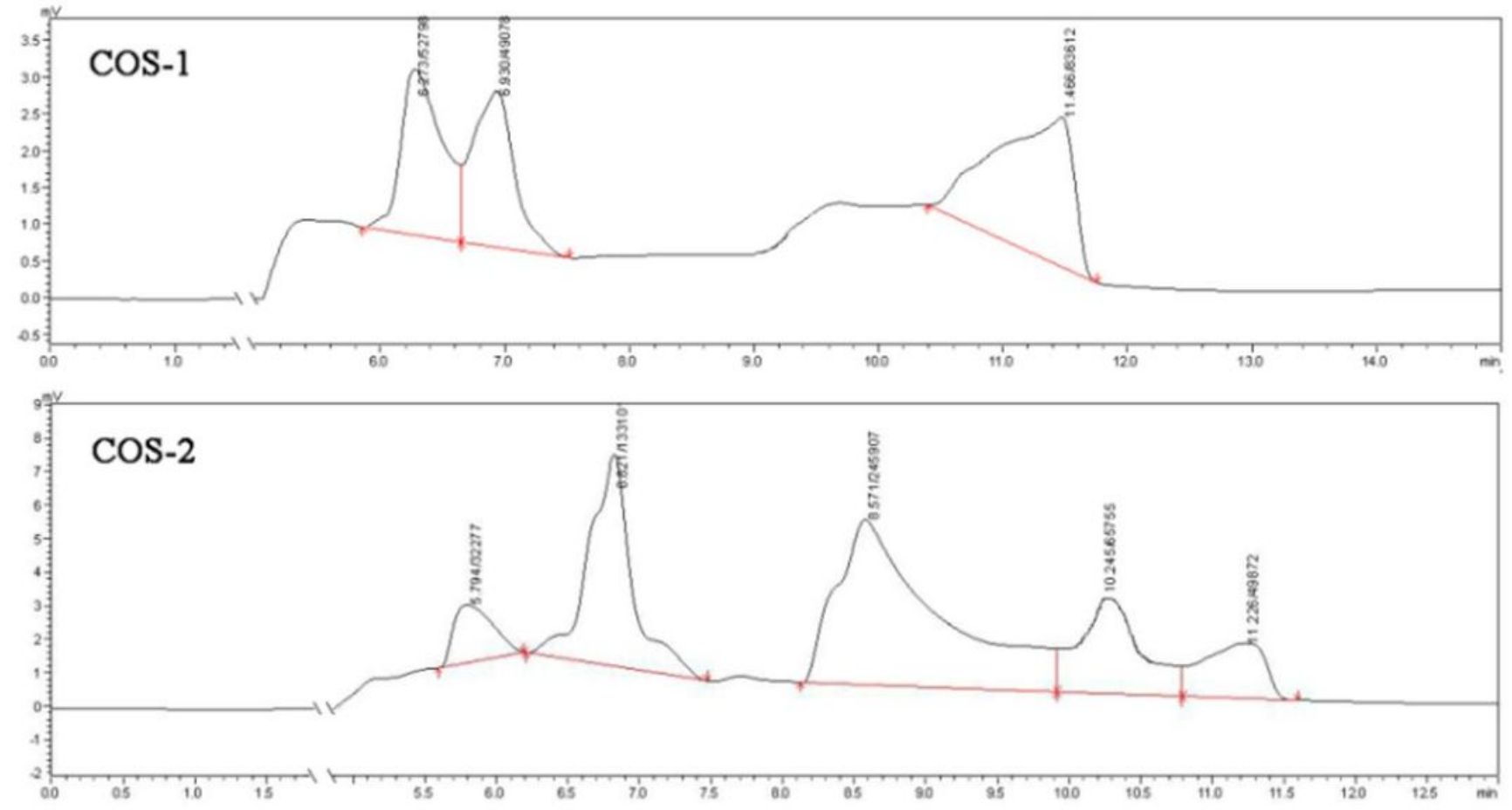

Figure 4

Liquid chromatography of COS-1 and COS-2. 

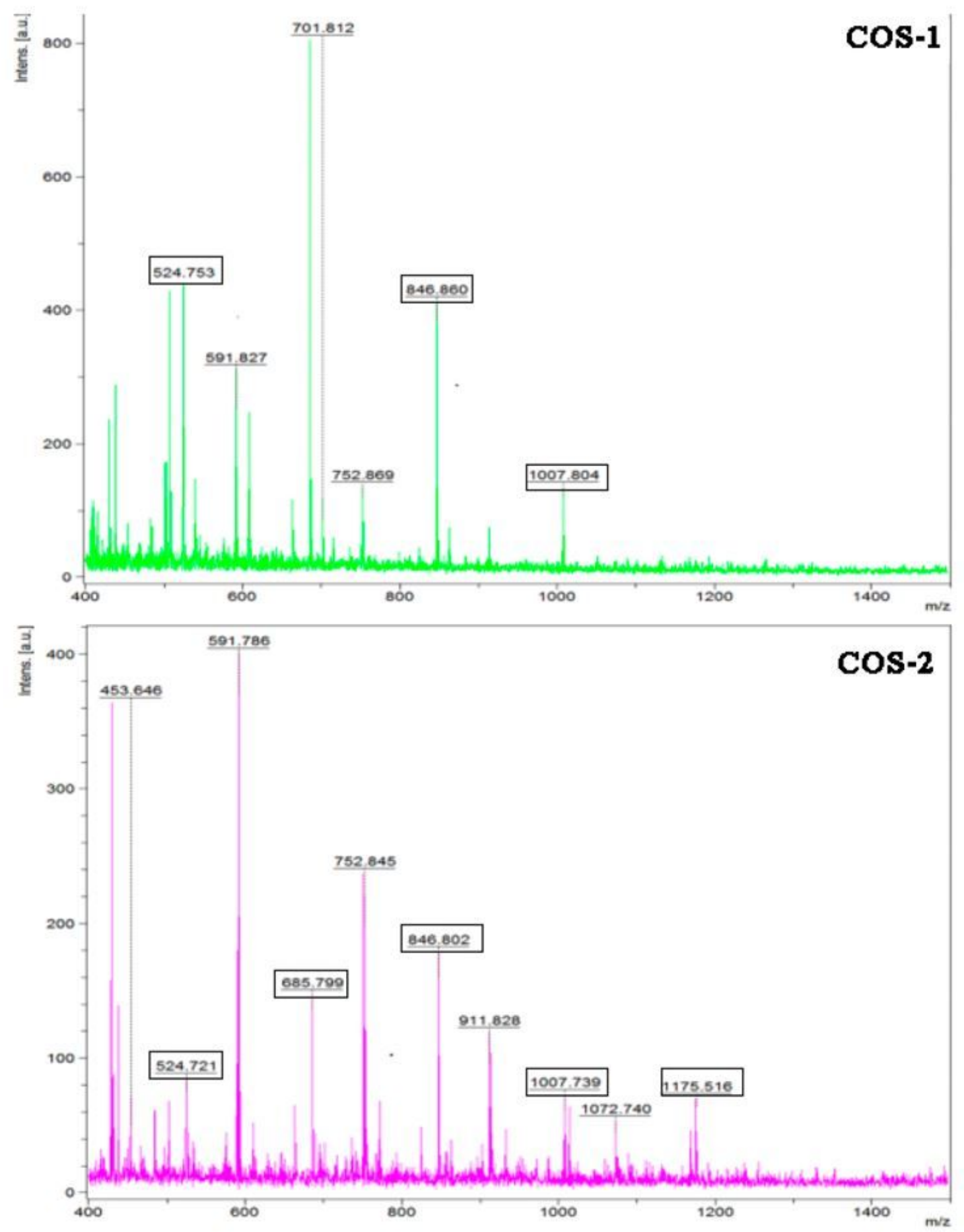

Figure 5

MALDI-TOF/MS spectrum of COS-1 and COS-2 in positive ion mode. 


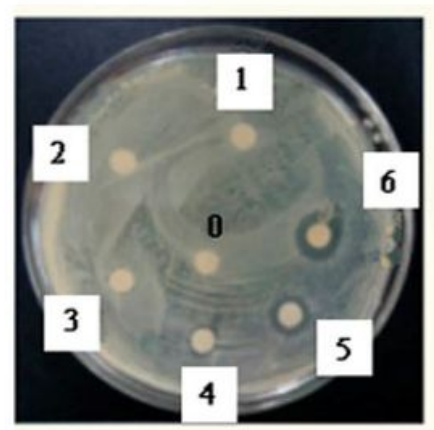

(a)

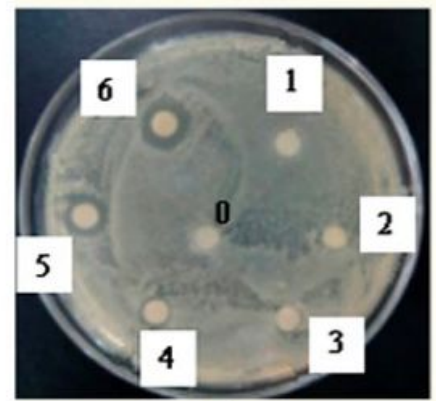

(c)

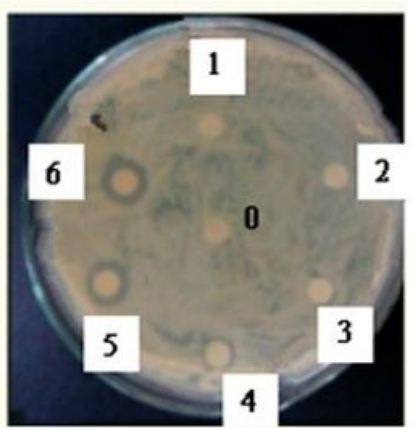

(b)

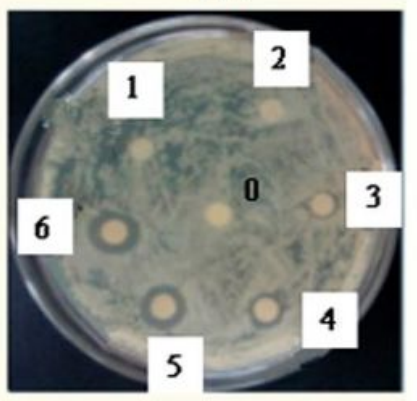

(d)

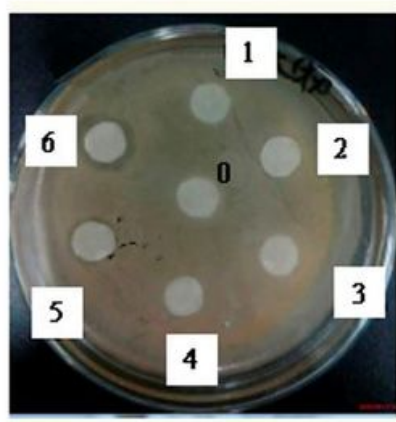

(a)

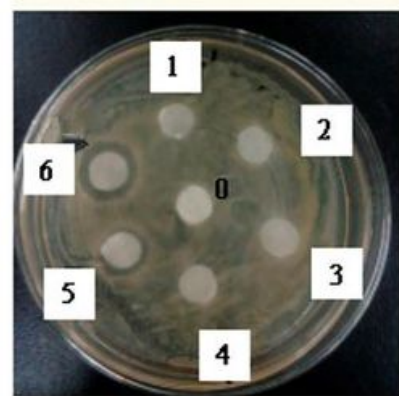

(c)

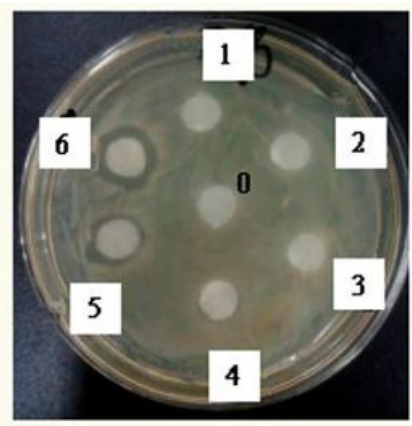

(b)

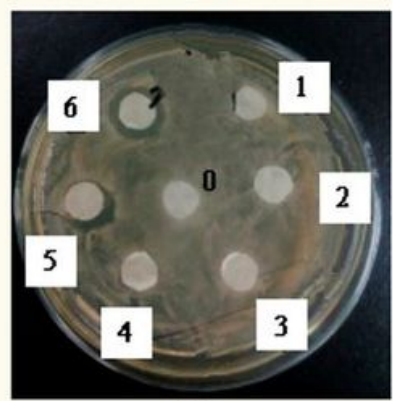

(d)

Cos-1

$\cos -2$

Figure 6

Growth of (a) Escherichia coli, (b) Staphylococcus aureus, (c) Bacillus subtilis, (d) Salmonella bacilli in agar plate with COS-1 and COS-2. 